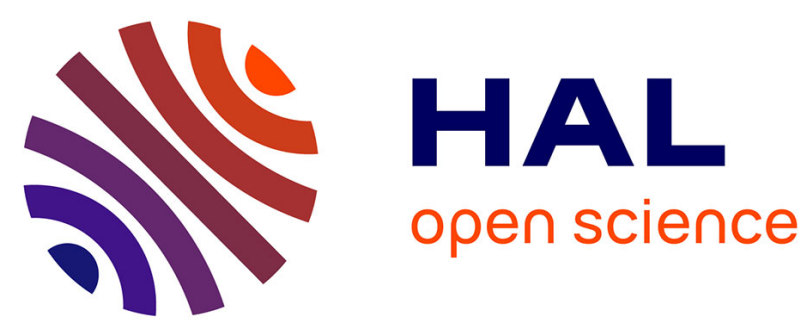

\title{
LPCVD Pyrocarbon Coating on Unidirectional Carbon Fiber Yarns: an Efficient Interphase for Aluminium Matrix Composites
}

Pierre Bertrand, M. Vidal-Setif, R. Mevrel

\section{- To cite this version:}

Pierre Bertrand, M. Vidal-Setif, R. Mevrel. LPCVD Pyrocarbon Coating on Unidirectional Carbon Fiber Yarns: an Efficient Interphase for Aluminium Matrix Composites. Journal de Physique IV Proceedings, 1995, 05 (C5), pp.C5-769-C5-776. 10.1051/jphyscol:1995591 . jpa-00253953

\section{HAL Id: jpa-00253953 https://hal.science/jpa-00253953}

Submitted on 1 Jan 1995

HAL is a multi-disciplinary open access archive for the deposit and dissemination of scientific research documents, whether they are published or not. The documents may come from teaching and research institutions in France or abroad, or from public or private research centers.
L'archive ouverte pluridisciplinaire HAL, est destinée au dépôt et à la diffusion de documents scientifiques de niveau recherche, publiés ou non, émanant des établissements d'enseignement et de recherche français ou étrangers, des laboratoires publics ou privés. 


\title{
LPCVD Pyrocarbon Coating on Unidirectional Carbon Fiber Yarns: an Efficient Interphase for Aluminium Matrix Composites
}

\author{
P. Bertrand, M.H. Vidal-Setif and R. Mevrel \\ ONERA, Direction des Matériaux, BP. 72, Châtillon cedex, France
}

\begin{abstract}
In order to optimize the interfaces in carbon fiber (high resistance Toray T800) reinforced aluminium matrix composites, a pyrolytic carbon $(C p)$ layer has been developed by a CVD process using a hot wall reactor operating at reduced pressure. The $\mathrm{Cp}$, which has a weak shear strength, is introduced to promote adequate debonding at the fiber/matrix interface.

In a first step, classical CVD studies are conducted on planar carbon substrates with a parametric investigation of the effects of temperature, pressure, reactant flow rates on the growth rate and morphology of the coating. For $\mathrm{Cp}$, obtained form thermal decomposition of ethylene, a very high activation energy $(310 \mathrm{~kJ} / \mathrm{mol})$ and a decrease in coating growth rate with the reactant residence time indicate that the reaction limiting step occurs in the gaseous phase. The carbon coatings exhibit a macroscopic stratified morphology which could promote internal delamination.

In a second step, deposition parameters have been optimized to ensure a good infiltration of 6000 filaments yarns. Finally, the influence of carbon underlayer on the mechanical properties of coated fibers is determined by tensile tests on monofilaments and interpreted in terms of Weibull distribution. The results on aluminium composites confirm the beneficial role of mechanical fuse played by the $\mathrm{Cp}$ coating.
\end{abstract}

\section{INTRODUCTION}

The development of metal matrix composite materials is almost entirely dependent on the interest of aeronautic and aerospace industries. Their aim is to obtain lighter spacecrafts and to use these materials in drastic conditions (temperature, mechanical strain).

Concerning carbon fiber reinforced aluminium matrix composites, some problems have slowed down their development. Indeed, during elaboration, a chemical reaction appears between the carbon of the fibers and the aluminium of the matrix leading to the formation of a brittle zone made of $\mathrm{Al}_{4} \mathrm{C}_{3} \mathrm{crystals}$. On the one hand, $\mathrm{Al}_{4} \mathrm{C}_{3}$ crystals play a role of fixing point that allow the strain transmission. On the other hand, they act as stress concentrating spots provoking the initiation and propagation of cracks into adjacent fibers which contribute to the composite strength reduction.

One of the solutions chosen at ONERA to prevent fiber/matrix reaction is to deposit a thin film on each fiber in order to protect them.

Protecting the fiber with a film implies the understanding of the role played by the interphase constituted by the coating. This interphase has to meet several requirements :

* to ensure physical continuity between fiber and matrix

* to transfer efforts

* to allow deviation cracks (role of mechanical fuse)

* to make wettability between carbon fiber and aluminium matrix easier

* to avoid disastrous reaction between fibers and matrix.

Pyrolytic carbon coating (Cp) seems to be a good choice to fullfil these requirements. Indeed, Cp is 
well-known for its poor chemical reactivity due to its microstructure made of graphite basal planes parallel to the substrate. Moreover its weak shear strength is likely to promote adequate debonding at the fiber/matrix interface.

$\mathrm{Cp}$ has been deposited on carbon fiber yarns (T800 HB Toray, 6000 filaments, diameter $=5 \mu \mathrm{m}$ ) and on SCS0 (SiC fiber from Textron, diameter $=140 \mu \mathrm{m}$ ) using low pressure chemical vapor deposition. This process is one of the most convenient to reach an homogeneous coating on each filament of the yarn. In this paper, our interest is focused on the kinetics and microstructural studies of Cp coating. Besides, a special attention is paid to the infiltration of filaments yarns. The effect of this coating on the composite mechanical properties is also discussed.

\section{EXPERIMENTAL METHODS}

The deposits are carried out in a low pressure tubular vertical reactor equipped with an alumina tube. This inductive-heated hot wall reactor has been already described in details in a previous paper [1]. The fibers handling system is composed of 2 motorized spools (a high one and a low one) that allow the fiber to pass through the deposition zone in both directions. The process is totally automated and computer controlled.

The kinetic study of $\mathrm{Cp}$ was realised by recording the substrate mass variations as a function of time with a vacuum microbalance installed in place of the high spooling device.

Unidirectional metal matrix composite plates $\mathrm{T} 800 / \mathrm{Al} 4.5 \mathrm{Mg}$ (wt.\%) were fabricated using a liquid phase hot pressing process developed at ONERA [2]: the processing temperature was $645^{\circ} \mathrm{C}$ with a hydrostatic pressure of $15 \mathrm{MPa}$ and a time of contact between liquid metal and fibers of about 60 seconds.

\section{RESULTS AND DISCUSSIONS}

This study was engaged to optimize processing conditions (temperature, pressure, gas flow rates) to obtain and to ensure a good infiltration of T 800 yarns (containing 6000 fibers). In order to obtain sufficiently high growth rates, alcenes were preferred to alcanes as precursors of $\mathrm{Cp}$.

\subsection{Deposition mechanism}

The formation of $\mathrm{Cp}$ from hydrocarbons is a rather complicated process and its mechanism is far from being understood at the molecular level although several kinetic models have been proposed to fit the experimental results [3]. This mechanism complexity comes from the great sensitivity on the processing conditions of parameters such as hydrocarbon thermal decomposition, homogeneous nucleation, polymerisation, condensation, chemisorption phenomena which are involved at the same time in the process. Moreover, the great number of gaseous species which coexist in such carbon-hydrogen systems make even more difficult to give a precise chain mechanism leading to the coating deposition.

So we tried, at first, to determine in our experimental conditions the slowest step of the process which controls the deposition rate.

For both ethylene and propylene precursors, the logarithm of deposition rate $(\mathrm{mg} / \mathrm{h}$ ) is plotted in figure 1 as a function of reciprocal temperature. These Arrhenius plots exhibit 2 values for the slowest stage activation energy which are, respectively for ethylene and propylene, about $310 \pm 30 \mathrm{~kJ} / \mathrm{mol}$ and 270 $\pm 50 \mathrm{~kJ} / \mathrm{mol}$. According to these results, the deposition rates are related to temperature and pressure by the following expressions :

$$
\begin{array}{ll}
\mathrm{v}(\mathrm{mg} / \mathrm{h})=3.88^{*} 10^{9} \mathrm{e}^{-(310,000 / \mathrm{RT})} \mathrm{P}_{\mathrm{CH} 4} & \text { for ethylene } \\
\mathrm{v}(\mathrm{mg} / \mathrm{h})=4.77^{*} 10^{8} \mathrm{e}^{-(270,000 / \mathrm{RT})} \mathrm{P}_{\mathrm{CH}, 6} \text { for propylene }
\end{array}
$$

From a series of experiments performed with varying the ethylene partial pressures and keeping the total flow rate constant, the order of the reaction was found to be approximatively equal to 1 ( figure 2). 
Figure 3 shows that the deposition rate decreases when the total gas flow rate increases. This result seems to show, if we interpret it in the light of the influence of precursor residence time, the importance of reactions generated in the gaseous phase as far as the deposition rate of $\mathrm{Cp}$ is concerned. Moreover, the activation energy values obtained experimentally are similar to those reported by Kunugi et al $[4,5]$ and corresponding to the radical initiation reactions of precursors decomposition. This seems to confirm, as it was also suggested by Chin [6], that the limiting step in Cp coating deposition, is not a surface reaction, as it is generally the case in classical CVD processes, but the gaseous phase precursors radical decomposition.

Nevertheless, we must keep in mind that the activation energy found doesn't necessarily represent a single reaction. It can include several reactions having similar rates.

\subsection{Morphological study}

In order to study the morphological evolution of the coating as a function of the position inside our reactor, Cp coating was deposited on a static SCSO fiber (Textron SiC fiber) during 2 hours.

The results and conditions are summarized in table 1. At the gas entrance, the coating does not show any specific feature and simply replicates the fiber surface. Up to a position of $120 \mathrm{~mm}$, the coating presents a smooth surface and an apparently dense structure. Above this position, some columns originating from the fiber surface appear inside the coating and are characterised by the presence of nodules. The number of these columns increases up to a position of $240 \mathrm{~mm}$ where the structure becomes totally columnar. This morphology is called mononuclear structure [7]. At the gas exhaust, a more porous structure, characteristic of a dendritic growth and called regenerative can be observed (figure 4)[7].

Except for this last structure, all the coatings exhibit the "Maltese cross" under polarized light optical microscopy, indicating that $\mathrm{Cp}$ forms with its basal planes parallel to the substrate. The macroscopic stratified structure observed on Cp coating fracture surfaces (figure 5) seems to confirm this growth mode.

These morphological texture changes can be attributed to the evolution of gaseous species concentrations as a function of the position in the reactor. This evolution increases the probability of formation of large germs at the origin of the column development. This formation occurs specifically on the fiber surface and seems to confirm a catalytic effect of the surface because the particles resulting from gaseous phase nucleation in the reactor do not reach sufficient size to form these columns. Only at the gas exhaust, they seem to reach this critical size and generate continuously, during the coating process, the columns development which promote the dendritic growth.

In parallel with the morphological evolution, we can notice an increase in the coating deposition rate (table 1). Two assumptions could explain this variation. The formation of longer chain hydrocarbons as a result of the precursors decomposition can affect the initiation step of the reaction. So, new reactions of decomposition energetically more favorable may occur and add to the previous ones to increase the deposition rate. Secondly, if the initiation step is not too modified, it is likely that propagation reactions occur from longer chains with, as a consequence, a higher deposition rate.

X-Ray diffraction patterns performed on two Cp-coated $\mathrm{SiC}$ flat substrates, one located in the upper zone, the other in the lower zone of the reactor, reveal a decrease in FMWH of the (002) peak when moving away from gas entrance. According to Scherrer law (i.e. assuming an internal stress effect neglible), the corresponding crystallite sizes along c-axis amount to $2.2 \mathrm{~nm}$ and $3.3 \mathrm{~nm}$ for the lower and the upper positions respectively. That means that, during continuous treatment on fiber, we may expect an evolution of the microstructure as a function of coating thickness.

\subsection{Experimental conditions influence on deposition rate}

A series of coatings on SCS0 fiber was achieved with a continuous treatment rate equal to $1 \mathrm{~m} / \mathrm{h}$ to determine the operating conditions influence on deposition rate. Table 2 shows growth rate ratios (in terms of coating thickness) normalized with respect to experiment 1 value. These results indicate that high deposition rates were obtained when the total flow rate was reduced and the pressure or the 
temperature increased. Besides, these rate increases are accompanied by a morphological change of the coating from a dense structure (experiment 1) to mononuclear ones (other experiments). The same evolution is recorded for coatings on T800 carbon fiber. As a consequence, the morphology control can be obtained by a growth rate regulation.

\subsection{Yarns infiltration}

The difficulties encountered during infiltration of a yarn come from the fact that the experimental conditions have to be adjusted in order to allow gaseous species to diffuse inside the yarn before reacting on fiber surface. This adjustment corresponds with a decrease in the deposition rate and therefore a longer treatment duration.

The preliminary infiltration tests conducted on FT500 yarn (diameter $=10 \mu \mathrm{m}, 3000$ fibers) show very little variation in thickness between fibers located near the center and those at the periphery of the yarn, with a Cp coating thickness up to $1 \mu \mathrm{m}$ on each fiber. The experiments carried out in the same conditions on T800 yarns (which are characterized by a larger fiber area and thinner pore sizes) lead to a very limited infiltration. During long duration treatments, external fibers are entirely bridged. So, access to the core is prevented and only the coating on the external fibers keeps on growing. Decreasing deposition rate allows a better infiltration. For thick coatings, the compromise between continuous treatment rate and satisfactory infiltration lead to a core thickness of $0.6 \mu \mathrm{m}$ and a periphery thickness of $0.9 \mu \mathrm{m}$ (figure 6). For thinner coatings, we can expect a reduction of this inhomogeneity. However, this compromise allows to reach continuous treatment rate of $2,5 \mathrm{~m} / \mathrm{h}$ in the case of a $100 \mathrm{~nm}$ coating on each fiber of a 6000 filaments yarn.

\subsection{Mechanical results}

Tensile tests performed on sized T800 monofilaments and Cp-coated T800 fibers, reveal practically no effect of the successive treatments involved in the deposition of the coating (figure 7). Despite the large number of filaments tested (100 on each case), the slight difference in Weibull modulus is not thought to be significant. The $\mathrm{Cp}$ coating does not therefore affect the tensile strength of the fibers.

\subsection{Application to composites}

Plates of composites $\mathrm{Al} 4.5 \mathrm{Mg} / \mathrm{T} 800 / \mathrm{Cp}$ (62\% fiber volume fraction) were fabricated using fibers coated continuously and their tensile strengths compared to those of composites containing uncoated fibers (specimen dimensions : $80 * 8 * 1 \mathrm{~mm}^{3}$ ). With a pyrolytic carbon coating between fibres and metallic matrix, tensile strengths as high as $1800 \mathrm{MPa}$ have been reached, significantly superior to the $300 \mathrm{MPa}$ obtained without coating [8].

Rupture surface associated with these tests show a planar fracture surface in the case of uncoated fiber indicating catastrophic crack propagation. On the opposite, in the case of Cp-coated fibers, pull out is observed showing that $\mathrm{Cp}$ has played its role of mechanical fuse (figure 8).

Regarding the the $\mathrm{Al}_{4} \mathrm{C}_{3}$ formation, M.E.T. examinations $[9,10]$ reveal that, because of its particular microstructure, $\mathrm{Cp}$ is less reactive than T800 fibers, confirming the expected diffusion barrier role of this coating.

\section{CONCLUSION}

The study of Cp deposition by a low pressure CVD continuous process has lead to two types of results: on the one hand, the influence of CVD operating conditions on the Cp growth rate and morphology has been extensively described on SCSO fiber and can be applied to carbon fiber. On the other hand, a proper set of experimental conditions $\left(\mathrm{P}=3000 \mathrm{~Pa}, \mathrm{~T}=1398 \mathrm{~K}, \mathrm{C}_{2} \mathrm{H}_{4} / \mathrm{Ar}=2 / 3\right)$ has been selected to infiltrate 6000 filaments yarns with a satisfactory homogeneity even for thick coatings (about $1 \mu \mathrm{m}$ ) and an adequate morphology.

This coating appears to be of very great interest for aluminium matrix composites as it acts both as a mechanical fuse and a diffusion barrier. So, it avoids to put a coating constituted of two different layers which increases the complexity and the cost of the fabrication process. However, we have some 
indications that in more drastic conditions (large pieces fabrication implying long contact time between Cp coating and matrix, or thermal treatments on composites), pyrocarbon chemical inertia will be not sufficient to avoid detrimental formation of $\mathrm{Al}_{4} \mathrm{C}_{3}$. In that case, we think that an additional chemical barrier layer $\left(\right.$ as $\mathrm{TiB}_{2}$ ) must be put down on the pyrocarbon.

\section{Acknowledgments}

The contributions of C. Diot (X ray diffraction), J.C. Daux (composite elaboration), J.L. Raviart (metallographic examinations) and M. Rabinovitch for helpfull discussions are gratefully acknowledged.

\section{References}

[1] Vidal-Setif M.H., Gerard J.L., Proc. Euro CVD 8, Glasgow, Scotland, 1991, J. Phys., 4, C2, 11 pp 681-88

[2] Rabinovitch M., Daux J.C., Raviart J.L., Mevrel R., Proc. ECCM4, Stuttgart, West Germany (1990) pp $405-410$

[3] Walker P.L.Jr, Chemistry and physics of carbon, vol 5, 1969

[4] Kunugi Taiseki, Tomoya Sakai, Ind. Eng. Chem. Fundam. 8, 3 (1969)

[5] Kunugi Taiseki, Tomoya Sakai, Ind. Eng. Chem. Fundam. 9, 3 (1970)

[6] Chin J., 82 Ann. Meeting of Am. Ceram. Soc., 1980, Chicago

[7] Le groupe français des carbones, Les Carbones, tome 2, 1965

[8] Vidal-Setif M.H., Rabinovitch M., to be published

[9] Perez O., Patriarche G., Lancin M., Proc. EUROMAT, Paris, France, 1993

[10] Rabinovitch M., Vidal-Setif M.H., Daux J.C., Raviart J.L., Mevrel R., Proc ICCM9, Madrid, Spain (1993), vol 1, p 683-90

\begin{tabular}{|c|c|c|c|c|}
\hline $\begin{array}{l}\text { Position in the } \\
\text { renctor }\end{array}$ & $\begin{array}{c}\text { Temperature } \\
\left({ }^{\circ} \mathrm{C}\right)\end{array}$ & $\begin{array}{c}\text { Thickness } \\
\text { (1 } \mathrm{km})\end{array}$ & $\begin{array}{l}\text { Residence } \\
\text { time (s) }\end{array}$ & Structure \\
\hline gas entrance & 860 & - & & - \\
\hline $40 \mathrm{~mm}$ & 1001 & - & 0,054 & - \\
\hline $80 \mathrm{~mm}$ & $10 \$ 2$ & 2 & 0.102 & $\begin{array}{c}\text { dense } \\
\text { structure }\end{array}$ \\
\hline $120 \mathrm{~mm}$ & 1116 & 4 & $0,1+5$ & $\begin{array}{l}\text { dense } \\
\text { structure }\end{array}$ \\
\hline $160 \mathrm{~mm}$ & 1122 & 18 & 0,189 & $\begin{array}{l}\text { columiar } \\
\text { growth }\end{array}$ \\
\hline $200 \mathrm{~mm}$ & 1104 & 40 & 0,233 & $\begin{array}{l}\text { columnar } \\
\text { growth }\end{array}$ \\
\hline $220 \mathrm{~mm}$ & $10 S 1$ & 50 & 0,255 & $\begin{array}{l}\text { columnar } \\
\text { groweth }\end{array}$ \\
\hline $240 \mathrm{~mm}$ & 1053 & & 0,277 & $\begin{array}{l}\text { columnirr } \\
\text { growth }\end{array}$ \\
\hline $280 \mathrm{~mm}$ & 952 & 64 & 0,323 & $\begin{array}{l}\text { columnar } \\
\text { growth }\end{array}$ \\
\hline gas exhaust & 860 & $=60$ & 0,35 & $\begin{array}{l}\text { dendritic } \\
\text { growth }\end{array}$ \\
\hline
\end{tabular}

Table 1 : Evolution of coating thickness and structure as a function of the position in the reactor $\left(\mathrm{P}=4500 \mathrm{~Pa}, \mathrm{~T}=1398 \mathrm{~K}, \mathrm{C}_{2} \mathrm{H}_{4} / \mathrm{Ar}=2 / 3\right)$ 


\begin{tabular}{|c|c|c|c|c|c|}
\hline $\begin{array}{c}N^{\circ} \\
\text { exp. }\end{array}$ & $\begin{array}{c}\text { Temperature } \\
\left({ }^{\circ} \mathrm{C}\right)\end{array}$ & $\begin{array}{c}\text { Pressure } \\
(\mathrm{Pa})\end{array}$ & $\begin{array}{c}\text { Flow rate Ar } \\
(\mathrm{ml} / \mathrm{mn})\end{array}$ & $\begin{array}{c}\text { Flow rate } \mathrm{C}_{2} \mathrm{H}_{4} \\
(\mathrm{ml} / \mathrm{mn})\end{array}$ & $\begin{array}{c}\text { deposition nate meio } \\
\text { (thickness } \mu \mathrm{m})\end{array}$ \\
\hline 1 & 1125 & 3000 & 600 & 400 & $1(0,6)$ \\
\hline 2 & 1125 & 4000 & 600 & 400 & $5(3)$ \\
\hline 3 & 1125 & 4500 & 600 & 400 & $8,3(5)$ \\
\hline 4 & 1125 & 3000 & 300 & 200 & $11(6,6)$ \\
\hline 5 & 1125 & 3000 & 500 & 500 & $2(1,2)$ \\
\hline 6 & 1175 & 3000 & 600 & 400 & $7(4,2)$ \\
\hline 7 & 1100 & 4500 & 600 & 400 & $3(1,8)$ \\
\hline
\end{tabular}

Table 2 : Influence of operating conditions on deposition rate (continuous treatment rate $1 \mathrm{~m} / \mathrm{h}$ )

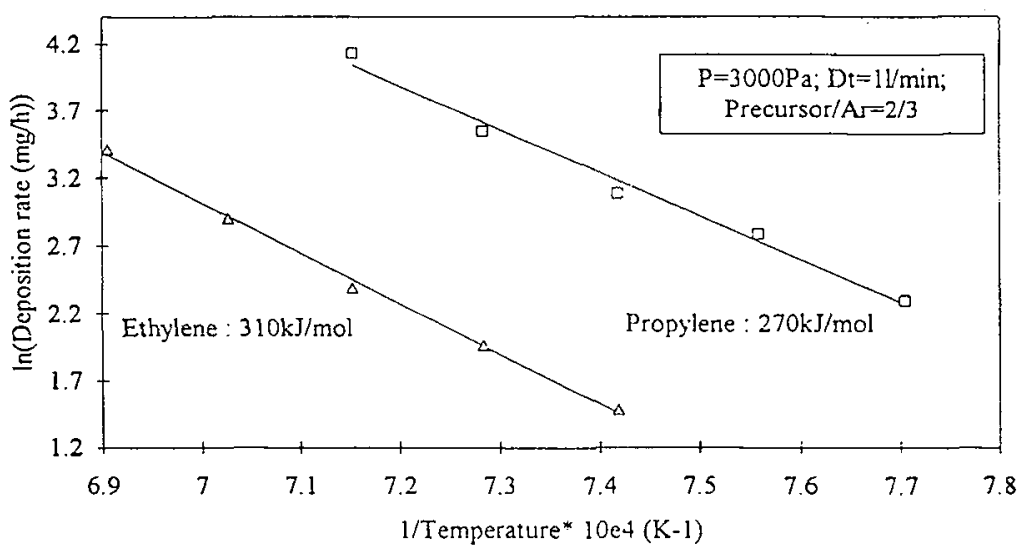

Figure 1 : Arrhenius plots for ethylene and propylene precursors

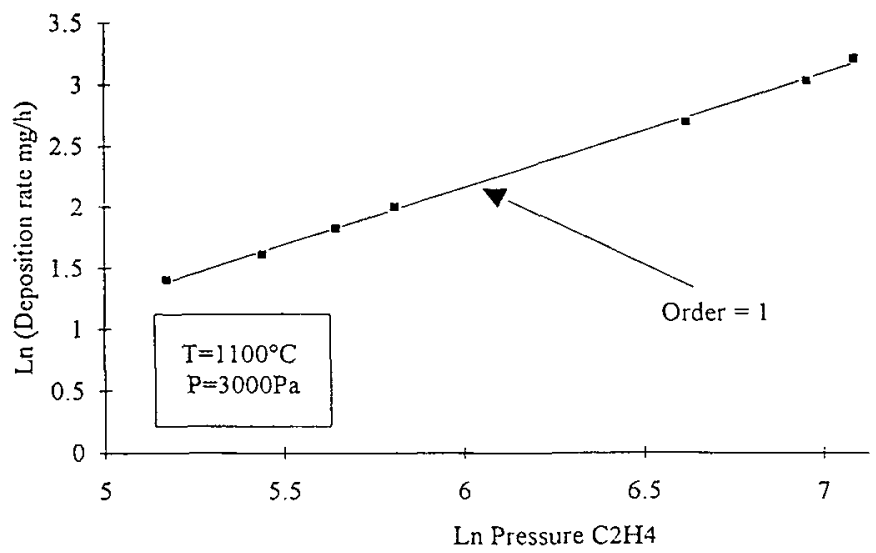

Figure 2 : Reaction order for ethylene precursor 


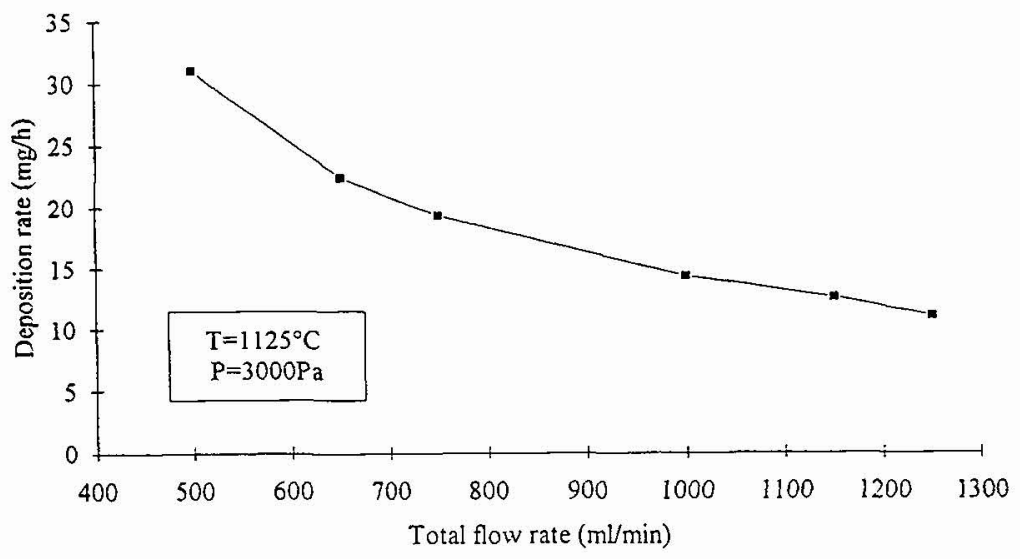

Figure 3 : Deposition rate of carbon as a function of total flow rate (ethylene)

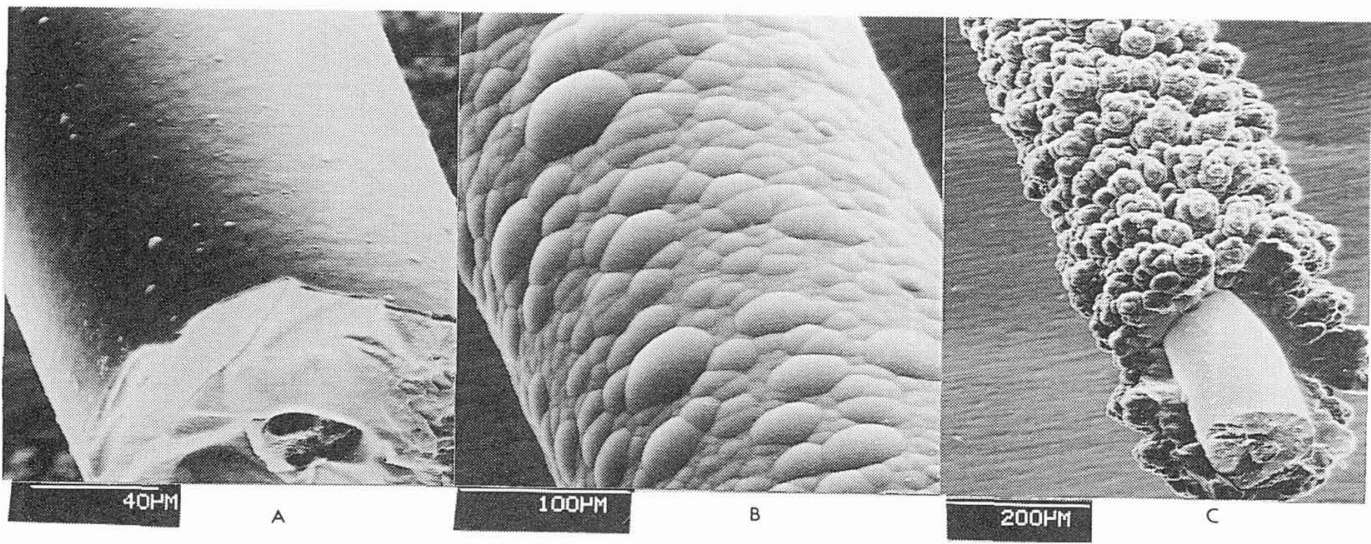

Figure 4 : Morphological evolution of a carbon coating as a function of the position in the reactor $\left(\mathrm{P}=4500 \mathrm{~Pa}, \mathrm{~T}=1398 \mathrm{~K}, \mathrm{C}_{2} \mathrm{H}_{4} / \mathrm{Ar}=2 / 3\right)$ a) $80 \mathrm{~mm}$ b) $\left.220 \mathrm{~mm} \mathrm{c}\right) 300 \mathrm{~mm}$

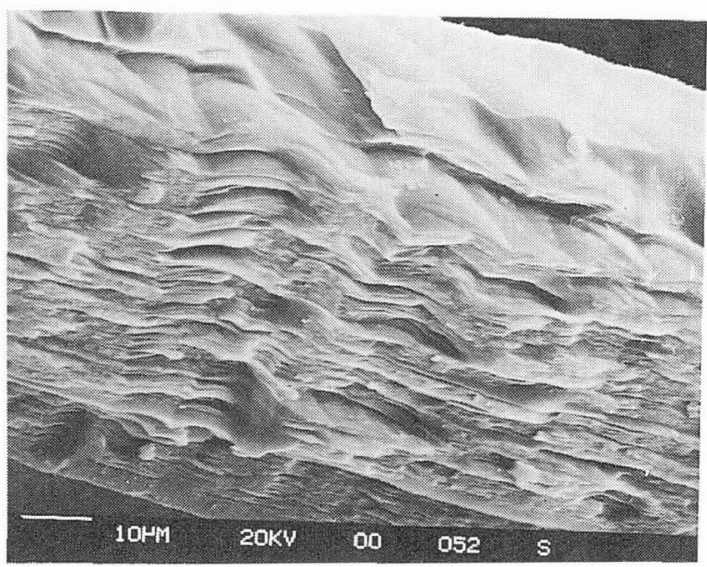

Figure 5 : Fracture surface of a carbon coating 


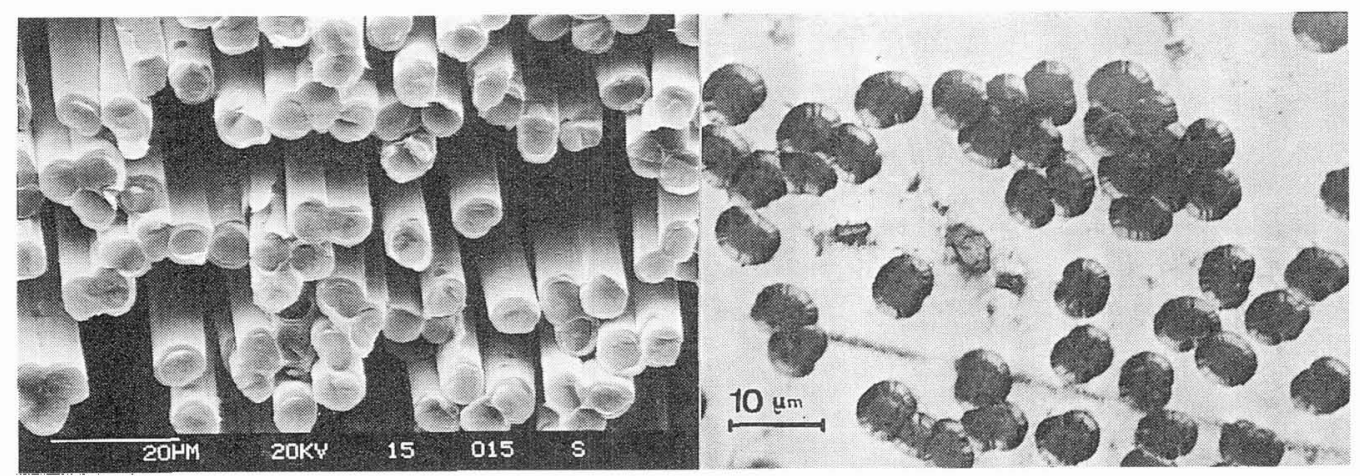

Figure 6 : Results of the T800 yarn infiltration $\left(\mathrm{P}=4500 \mathrm{~Pa}, \mathrm{~T}=1398 \mathrm{~K}, \mathrm{C}_{2} \mathrm{H}_{4} / \mathrm{Ar}=2 / 3, v=0.5 \mathrm{~m} / \mathrm{h}\right.$ )

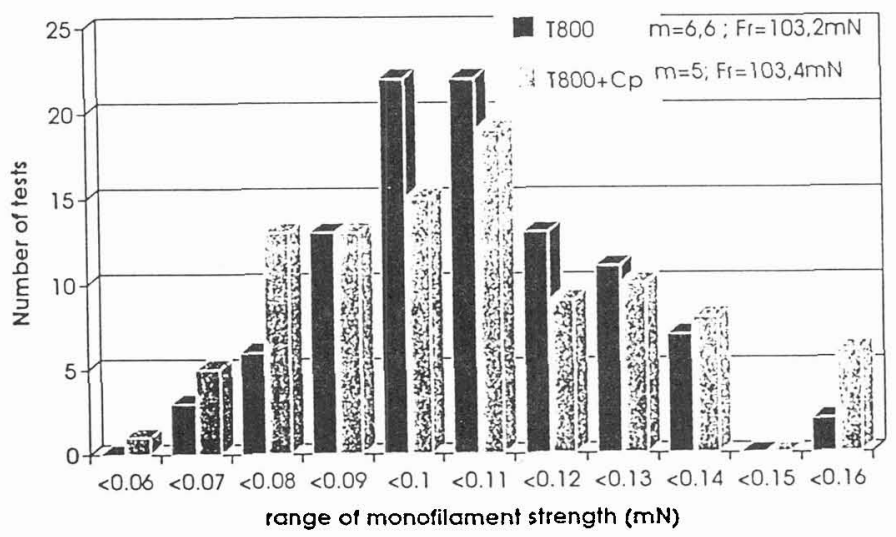

Figure 7 : Tensile strength Weibull distribution on monfilament (sized T800 and T800+Cp) $\mathrm{m}$ : Weibull modulus, $\mathrm{Fr}$ : average strength

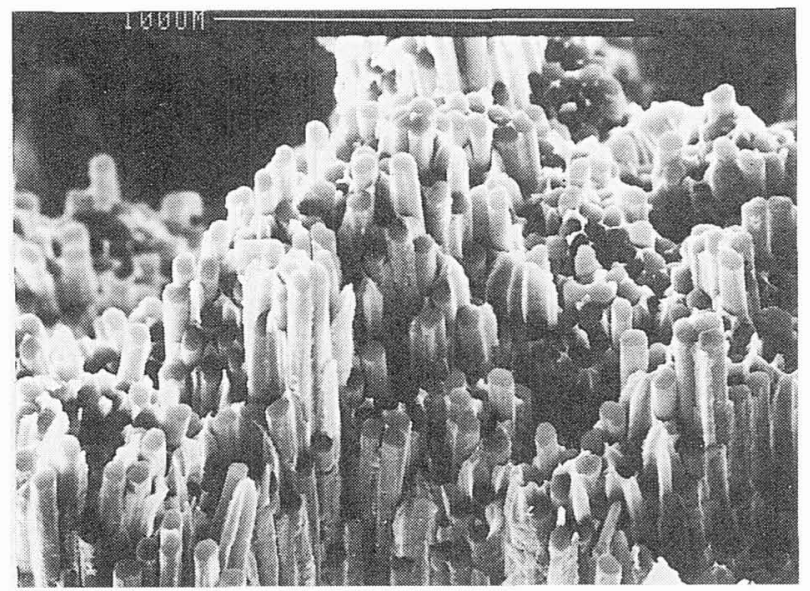

Figure 8 : Fracture surface of the composite $\mathrm{Al} 4.5 \mathrm{Mg}($ wt.\%)/ T800+Cp showing "pull out" 